\title{
Aproximación al estudio de los procesos de transformación de las ciudades históricas. La tematización
}

Pablo Millán-Millán. Pontificia Universidad Católica de Valparaíso, Viña del Mar, Chile. Universidad de Sevilla, Sevilla, España.

Luz Fernández $\boldsymbol{V}$. Universidad de Sevilla, Sevilla, España.

RESUMEN | Podemos afirmar que los centros históricos son los espacios urbanos más complejos y frágiles de la ciudad: en ellos convergen valores de tipo simbólico y social, compaginados con una fuerte degradación. Con el crecimiento de las ciudades y el abandono de los pueblos vinculados a labores agrarias, fundamentalmente, se fue dando cita en las zonas antiguas de las ciudades (zonas más populares) un número ingente de población. Esta elevada densidad poblacional fue demandando políticas higienistas y desarrollistas que se materializaron en intervenciones de apertura de los centros históricos, así como en la suplantación de construcciones antiguas por edificios en altura, acelerando con ello el valor del suelo. Estos procesos de colmatación, junto con el citado incremento del precio de los centros históricos, han ido haciendo de estos un interesante producto para el mercado. Ello, unido a los agentes de desarrollo turísticos, acelera un proceso de transformación que será necesario estudiar.

PALABRAS CLAVE | gentrificación, marketing urbano, patrimonio.

ABSTRACT | We could state that historical centers are the most complex and fragile urban spaces in our cities, given that they account for symbolic and social values while, at the same time, are increasingly degraded. The growth of the cities and the abandonment of rural villages affected the old centers of our cities, turning them into their most populated areas. This high population rate demanded developmental and hygiene policies that were materialized in interventions that opened historical centers, substituted older constructions by high-rise buildings, and increased land value. These processes, plus the afore-mentioned high price of the historical centers, have transformed them into an interesting market product. These facts, together with tourist development agents, have accelerated a phenomenon of urban transformation worth considering.

KEY WORDS | gentrification, urban marketing, heritage.

Recibido el 23 de marzo de 2012, aprobado el 27 de diciembre de 2012

E-Mail: Pablo Millán-Millán, pmillan1@us.es | Luz Fernández V., luzval@us.es 


\section{Introducción. Los centros históricos: shopping-mall tematizados}

Se trata de un cambio ambicioso: la calle République -arteria central que une ambos puertos-con sus cafetines vietnamitas, cuscus a toda hora $y$ sus inquilinatos, hasta ahora se parecia menos a los Campos Eliseos que a un barrio popular de París, como La Goutte-d'Or. Pero, precisamente, se felicita Foillard, "el centro de la ciudad está en vías de ser reconquistado" y su empresa, en manos del fondo anglosajón Lonestar, vinculado a la Caja de Ahorro y a la Société Général, participa en la avanzada de esta "reconquista": "En una de las manzanas se va a implantar una decena de letreros luminosos de las firmas francesas más prestigiosas en productos de lujo. Cuatrocientos mil turistas que viajan en cruceros pasan por Marsella todos los años, lo que constituye una ocasión que aprovechar por las cadenas, ya que podrán descender del barco y tener marcas modernas a una distancia que puede recorrerse a pie..."

(Ruffin, 2007)

Reflexionar sobre la condición de los centros históricos nos acerca inexorablemente a las diferentes intervenciones que se han hecho en Europa e Iberoamérica en los últimos años, así como a las transformaciones que en torno a ellos se han dado. Estamos en un territorio que se caracteriza por el número e importancia de centros históricos de diversa dimensión. La preocupación por el lugar que ocupan estos ámbitos patrimoniales en la ciudad es generalizada. Aunque el concepto en sí de centro histórico es muy reciente y surge en la década de los años sesenta, ya existía mucho antes una noción y conciencia del monumento aislado. La Carta de Atenas de 1931 recogerá este interés, definiendo dichas obras como "edificaciones emblemáticas que destacan como hitos dentro del paisaje urbano".

Posteriormente, en 1933, promovida por el Cuarto Congreso Internacional de Arquitectura Moderna (CIAM), se publicó una nueva Carta que asentaba los fundamentos de la nueva planificación en cuatro funciones: habitar, trabajar, recrearse y circular. Este modelo de ciudad chocará con la ciudad tradicional alojada en los centros históricos que, a su vez, serán vistos como insalubres, ineficientes y pretéritos. En Europa existen algunos antecedentes, ya que en 1961, en el Congreso Internacional de Vivienda y Urbanismo, el problema de los conjuntos y centros históricos fue tema central. Es una problemática generalizada.

Es necesario adquirir un conocimiento detallado e integral de la historia (...). El objetivo es establecer una relación armoniosa entre el hombre y la naturaleza, la tradición y el modernismo, el desarrollo de la cultura de las minorías étnicas, la ecología y la economía (Profesor Shao Yong, Universidad de Tongli y Centro de Investigación Nacional de Ciudades Históricas de China; citado en unesco, 2008, p. 21).

Las traducciones al castellano de todas las citas originalmente en otro idioma son de los autores. 
El taller de diseño urbano (octubre de 2006) formaba parte de un evento urbano más amplio que tenía como objetivo ser un ejercicio de planificación, consulta y comunicación para un diálogo constructivo entre interlocutores interesados en la revitalización sostenible del distrito histórico de Griffintown (Montréal, Bureau de Design, 2007).

La conservación de las poblaciones o áreas urbanas históricas solo puede ser eficaz si se integra en una política coherente de desarrollo económico y social, y si es tomada en consideración en el planeamiento territorial y urbanístico a todos los niveles. [Por consiguiente] el plan de conservación tratará de lograr una relación armónica entre el área urbana histórica y el conjunto de la población (Iсомоs, 1987, arts. 1 y 5).

No hay dos centros históricos iguales, por lo que habrá que tener en cuenta la especificidad del lugar y aprovechar el potencial del mismo. Estos valores inherentes serán los catalizadores de las estrategias que se desarrollarán. La pluralidad tipológica de ciudades históricas hace que se investigue, estudie y analice tal cuestión por todas las geografías y latitudes. "La necesidad de conciliar las exigencias del progreso urbano con la salvaguarda de los valores ambientales, es ya hoy día una norma inviolable en la formulación de los planes reguladores a nivel local como nacional. En este sentido todo plan de ordenación deberá realizarse en forma que permita integrar al conjunto urbanístico de los centros o complejos históricos de interés ambiental" (Normas de Quito, 1967, IV, 1).

El mantenimiento del entorno histórico tuvo, en sus comienzos, motivaciones políticas. En Estados Unidos, este movimiento empezó inmediatamente antes de la Guerra Civil, como signo de la ansiedad reciente por impedir al principio y luego por sanar la desastrosa brecha que se abría en la unidad de la nación. Más tarde, el mantenimiento del entorno histórico se conectó, de un modo explícito, a la "americanización” del inmigrante extranjero que venía a profanarlo. Posteriormente, fueron añadiéndose nuevos motivos: corrección en las restauraciones arquitectónicas, investigaciones arqueológicas y, por último, atracción turística según que el disfrute de los lugares históricos se iba convirtiendo en fenómeno generalizado. Hoy en día, este placer se ha tornado en un gusto tan preestablecido que ha dado lugar a que las zonas urbanas enteras se hayan preservado y restaurado, y no ya solo para los turistas, sino para los propios residentes (Lynch, 1981, p. 186).

Igualmente se despertará este interés en Europa, pero no será hasta pasada la Segunda Guerra Mundial, tras la enorme destrucción de centros históricos y urbanos, cuando surja un gran período de reflexión. En París, en 1957, se da un paso significativo al convocarse el Primer Congreso Internacional de Arquitectos y Técnicos, cuyos incipientes planteamientos se concretan en 1964 en un segundo congreso, durante el cual se elabora la Carta Internacional para la Conservación y la Restauración de los Monumentos y Sitios, la llamada Carta de Venecia, cuyos postulados rigen, en esencia, las últimas décadas del siglo xx (Waisberg, 2004, p. 257).

Un año después, en 1965, con el apoyo de la UnEsco, se funda el Comité Internacional, conocido con las siglas Icomos (International Council on Monuments and Sites). Constituido por personas e instituciones no gubernamentales, asume 
la tarea de examinar los expedientes y designar a los expertos que informan de los casos de postulación a la nominación de patrimonio de la humanidad. La Carta de Venecia contendrá modificaciones sustanciales tanto en el concepto de patrimonio como en el tratamiento de las obras sujetas a protección, lo que la constituye una novedad respecto de lo pensado y escrito anteriormente. La Carta de Venecia, junto con los Coloquios de Quito, la Declaración de Bolonia, la Carta de Ámsterdam de 1975, la Recomendación de la UNESCO en Nairobi de 1975, etcétera, provocarán el efecto contrario, una reacción antimoderna contra la "renovación" de la ciudad heredada. Las secuelas de este proceso adverso son marcas en la ciudad que hoy en día se siguen desdibujando.

Los países latinoamericanos, en cuanto a la gestión, impacto económico y transformación de las ciudades históricas, han buscado un patrón compartido en el que la inversión privada, junto con la asociada al sector público permitan la conservación y el desarrollo de las áreas patrimonialmente declaradas. Podríamos decir que estos modelos han evitado la museificación y puesta en mercado de las áreas históricas de la ciudad. Estas figuras varían de una realidad a otra. El caso de México, por ejemplo, muestra el intento de unificar todas las entidades intervinientes en la ciudad declarada patrimonial. La búsqueda de la llamada "sostenibilidad financiera" ha sido uno de los intentos perseguidos como clave del éxito para el desarrollo de los programas en los centros históricos.

La declaración de México de 1982 mostraba el panorama de financiación para el desarrollo de las ciudades patrimonio unesCo, en el que se daba una gran relevancia al papel de la financiación internacional como importante agente para la conservación y el desarrollo. El caso de Quito es un buen ejemplo de las fases evolutivas de un proceso de revitalización de centros históricos: una primera fase orientada a frenar y revertir el proceso de deterioro en el centro, priorizando la eliminación de agentes externos, la rehabilitación del patrimonio histórico y el uso residencial del sector; y una segunda fase que busca dar sostenibilidad a todo lo conseguido, enfatizando el tratamiento de temas sociales y económicos clave (BID, 1994).

Los casos de Cartagena y Bogotá se han constituido en paradigmas de programas donde el proceso de deterioro patrimonial se ha detenido y contrarrestado en gran parte del centro histórico. Los proyectos que allí han tenido lugar se han caracterizado por acciones de rehabilitación patrimonial relativamente pequeńas y muy puntuales: énfasis en el abordaje de problemas sociales y económicos que afecten la calidad de vida en el centro; acciones integrales de recuperación de áreas de borde del casco histórico que se encuentran deterioradas y pueden afectar negativamente el proceso de revitalización del centro; y generación de suelo para la construcción de vivienda asequible a hogares de ingreso medio/medio-bajo.

En los últimos años se han sucedido numerosos trabajos en investigaciones de temas urbanos que han centrado su atención en las ciudades y centros históricos, como respuesta a numerosos factores que han mostrado la importancia de estas zonas de la ciudad para su revitalización. La traducción más directa de la revalorización de las ciudades históricas se ha centrado en nuevas inversiones, y nuevos y ambiciosos proyectos. Valparaíso, por ejemplo, está siendo objeto de numerosos trabajos 
de investigación ${ }^{2}$ y documentación que analizan la evolución de la ciudad porteña, desde su declaración como Patrimonio de la Humanidad por la unesco hasta hoy.

\section{Presente-pasado, presente-futuro}

La imposibilidad de uso tiene su lugar tópico en el modo progresivo, las potencias espirituales que definian la vida de los hombres - el arte, la religión, la filosofía, la idea de naturaleza, incluso la politica- se han ido retirando dócilmente hacia el Museo. Museo no designa aqui un lugar o un espacio físico determinado, sino la dimensión separada a la que transfiere aquello Museo. La museificación del mundo es hoy un hecho consumado. Una tras otra, de que en el pasado fue percibido como verdadero y decisivo, y ya no lo es. El Museo puede coincidir, en este sentido, con una ciudad entera (Évora, Venecia, declaradas por eso Patrimonio de la Humanidad), con una región (declarada parque u oasis natural) e incluso con un grupo de individuos (en cuanto representantes de una forma de vida que se ha extinguido). En términos generales, hoy todo puede volverse Museo, porque éste denomina simplemente la exposición de una imposibilidad de usar, de habitar, de experimentar.

(Agamben, 2005, p. 110)

Con esta cita de Giorgio Agamben centramos el tema que nos preocupa en la investigación. Abordamos el estado de la cuestión sobre el proceso de tematización o, como iremos definiendo a lo largo de estas líneas, el proceso de mercantilización. El texto de Agamben termina con una "trilogía de imposibilidades" que se dan en el medio "museificado". Esta tríada, que será explicada de forma minuciosa, consiste en la imposibilidad de usar, habitar o experimentar el patrimonio. Son características propias de los centros comerciales, aquellos cuyo único fin es el mercado. Compararemos estos centros comerciales del patrimonio, trozos de ciudad recualificados, con los shopping-malls, para extraer desde ahí puntos para el estudio. Analizaremos los paralelismos que se dan en ambos casos. Seguidamente, utilizaremos la conferencia de Peter Sloterdijk sobre los palacios de cristal, que pronunció en el marco del debate "Traumas urbanos. La ciudad y los desastres", para analizar junto con Fedor Dostoievsky el proceso de cristalización.

Los tejidos históricos de nuestras ciudades presentan dos riesgos extremos. Por un lado, la amenaza de una "degradación” física y marginalización social, que los convierte en zonas socialmente desplazadas y, a la postre, áreas urbanas residuales y guetos. Por otro lado, el gran peligro de la "tematización", con la consiguiente sustitución poblacional como paso previo a su entrada en el mercado. Es evidente que

2 The sustainability of urban heritage preservation: interventions to support economic and residential investments in urban heritage areas of Latin América and the Caribbean (RG-T1620): Case study Valparaiso, de Pablo Trivelli y Yasuyo Nishimura (2010); o el Informe Final de Evaluación del Programa de Rehabilitación y Desarrollo Urbano de Valparaíso (pRDUV), donde se analiza el impacto de las inversiones de dicho programa en la ciudad porteńa (Ministerio del Interior, Subsecretaría de Desarrollo Regional y Administrativo [SUBDERE], 2009). 
hay pasos intermedios y que ninguno de los extremos sería una alternativa deseable. El paradigma debería ser que la ciudad histórica siguiera como una pieza viva en la ciudad contemporánea, con características y valores específicos, con niveles de conservación, habitabilidad y diversidad (social y funcional) razonablemente elevados (López, 2008, p. 70). Aquí abordaremos el gran riesgo y la fragilidad que supone la incorporación de los centros históricos a las filas del mercado. Hay mucho publicado sobre los efectos sociales que están deviniendo de las intervenciones en los centros de las ciudades. Son muchos los análisis que tipifican, clasifican y encuadran las consecuencias que han tenido las modificaciones del tejido residencial de estas zonas, así como el cambio de uso de las mismas. Procesos como la gentrificación, cristalización y zonificación de las ciudades históricas han sido objeto de muchos estudios. Ahora, cuando la situación económica empieza a demandar atracción e identidad a la ciudad como caminos previos a movimientos turísticos, se hace necesario un análisis sobre el circunloquio que suponía hablar de puestas en valor cuando realmente se estaba hablando de mercantilizar el patrimonio histórico. Los datos sobre el turismo en el último periodo acentúan el poder seductor de este sector sobre las ciudades. España, según el Instituto de Estudios Turísticos (2012, p.18), ocupa el segundo lugar como país receptor de ingresos por este concepto después de Estados Unidos. Esto, que es algo que no pasa inadvertido a los políticos, será el gran motivo de las transformaciones físicas en las zonas históricas. Todos estos cambios se dan dentro del proceso de tematización, en el que las ciudades han visto una nueva forma de ser "atractivas", sin sopesar los riesgos que las transformaciones entrañan. Este peligro es típico de las zonas más monumentales y características de la ciudad. Los desarrollos habitualmente vienen precedidos o acompańados del envejecimiento y abandono de la población originaria. Las carencias físico-sanitarias que estas zonas han sufrido durante mucho tiempo son causa justificada para su abandono por parte de muchos de los residentes antiguos. Así, el tejido histórico se vacía, la ciudad se convierte en un contenedor "hueco", en un mero escenario. Será el potencial de la imagen de los grandes monumentos y la identidad que aportan los mismos a las ciudades los que den el interés y, por tanto, sirvan de escaparate al mercado.

Para explicar estas transformaciones y el fin buscado con ellas, hemos analizado la figura del shopping-mall. Este concepto del comercio es diferente al del centro comercial y al del museo. Es el nuevo concepto de plaza. Desde la fundación de las ciudades, la plaza -el ágora- era el lugar de encuentro, de intercambio, de estar: era, en definitiva, el espacio público (Innerarity, 2006). Su importancia radicaba en ser el centro de la ciudad que, a su vez, se correspondía con el punto más antiguo de esta. En las nuevas ciudades, la plaza era el lugar desde el cual se planteaba el trazado urbano, y que solía coincidir con su centro geográfico. Las plazas son los lugares que identifican el grueso del patrimonio de la ciudad; en la actualidad, sin embargo, están pasando por un proceso de marketing y puesta en venta, como iconos singulares de las ciudades. Son "trozos" de ciudad convertidos en auténticos mercados, en los que toda la estructura física se mantiene hermética a cualquier transformación. Ahí no se le da paso a la historia. Como dice P. Slóterdijk (2004), aquí solo ocurrirán meros "accidentes domésticos" (p. 10). Como veremos ahora 
detenidamente, ese será uno de los requisitos fundamentales del nuevo modelo de centro histórico.

a. Sin usar, sin habitar, sin experimentar. Así definía G. Agamben las nuevas cualidades del museo, y así serán extrapoladas estas cualidades al modelo de centro histórico. Aquí entenderíamos la definición augéiana de no lugar, espacio sin creación y sin sociedad, ya que no se puede crear sociedad sin la suma de experiencias personales, sin relaciones de habitar (Innerarity, 2001). Esta ciudad fragmentada que venimos describiendo desde los centros históricos es, en el momento actual, lo que vemos desarrollarse como centralización sin centralidad, lugares que han renunciado a ser identitarios, a ser lugares activos. En los centros de las ciudades vemos comercios, cafés, hoteles, plazas con su mercado e iglesia; en definitiva, lugares que, por lo reducido de la escala, pudiéramos decir que obligan a detener el tiempo y la actividad para acercar más la persona al medio, para meter un nuevo reloj en la historia de ese centro, un ritmo un poco perezoso y la atmósfera del domingo por la mañana (Augé, 2004). En cambio, observamos cómo lo que subyace en estos conglomerados de redes es la prisa, la individualidad y el desarraigo. Continúa diciendo M. Augé que si pudiéramos definir un lugar como un ámbito de identidad relacional e histórico, un no lugar sería todo lo contrario, es decir, un ámbito para el anonimato, que potenciaría la individualidad y sin historia presente. Todo ello nos muestra cómo un centro histórico en la contemporaneidad es un "no lugar" en el que la historia ha sido expulsada tras grandes procesos de especialización. Estas dinámicas de individualidad, agilidad y tematización acaban determinando el proceso de disolución urbana, donde los centros históricos de las ciudades también históricas han sido subyugados a los patrones de un nuevo urbanismo y forma de entender el patrimonio y el mercado.

Son muchos los autores que hablan de centros históricos como centros residenciales, ya que la mayor parte de estas superficies urbanas ha sido y es tejido destinado a ese uso. Es más, algunos incluso subrayan que la vivienda es un indicador de la recuperación de los conjuntos históricos (Álvarez, 2009). Realmente este podría ser un indicador válido si el uso residencial fuese unido al de ocupación de viviendas y tipologías tradicionales. Como hemos dicho anteriormente, las ciudades históricas sufren intensos fenómenos de expulsión de la población original, eliminando con ello un recurso patrimonial, como es el patrimonio intangible. Esta población se dispersa por la ciudad ocupando nuevas o diferentes tipologías habitacionales, y toda la memoria quedará callada con el desasosiego de no haberse visto nuevamente sembrada para las siguientes generaciones. El peso específico de esta gente no será más que el que tienen en sí mismas, su capacidad económica e influencia política, que en la mayor parte de los casos suelen ser muy escasas o casi nulas (Fernández, 2003). Esto traerá consigo una nueva forma de "habitar" los centros históricos, una novedosa manera de relacionarse con ellos. Son muchos los "archilab" y "Europan" que se han desarrollado en las ciudades históricas a fin de buscar y encontrar modos inéditos de acercarse a la compleja realidad que supone adentrarse en los cascos históricos de las ciudades. Ha habido muchos y diversos resultados en los que 
ya empiezan a aparecer palabras algo manidas y en decadencia por el continuo mal uso, como participación, proyectos participativos, etcétera. El nuevo tejido social que ocupa la ciudad histórica no generará nuevas formas de patrimonio inmaterial. Como hemos dicho anteriormente, estos nuevos moradores desempeñan un rol diferente, no el del ciudadano que habita y vive una ciudad, sino el del observador que vive una realidad paralela sin encarnarse en ese lugar. Serán la casualidad y las sinergias sociales las que se encarguen del bien inmaterial contemporáneo en un contenedor heredado. La ciudad que verdaderamente permanece, la que sobrevive a los cambios morfológicos, sociológicos o culturales, es la que va componiendo los quehaceres efímeros, las pasiones azarosas, los avatares infinitos que obedecen a una lógica desperdigada y sonámbula, cuyos protagonistas son un magma de desconocidos que viven toda su vida cruzándose unos con otros y, de vez en cuando, hasta sin querer.

b. Detenido en la historia. (Una historia que legitima el presente).

Según las tradiciones, Museo es el amigo, el discípulo, el maestro, el hijo o simplemente, el contemporáneo de Orfeo, del cual no parece ser sino una réplica en la leyenda ática. Tiene por padre a Antifemo o a Eumolpo, cuyos nombres indican que son cantores (Antifemo, según su nombre, sería el inventor del "canto de varias partes”), del mismo modo que él es, en lo esencial, el músico tipo. Parece que su madre fue Selene y que lo educaron las ninfas. Museo pasa por un gran músico, capaz de curar las enfermedades con sus melodías. Es también adivino, y a veces se le atribuye la introducción en el Ática de los misterios de Eleusis. Algunos lo consideraban el creador del verso dáctilo. Habría sido discípulo de Lino e incluso de Orfeo. Desde la antigüedad se le atribuían poemas de inspiración mística (Grimal, 1991, p. 368).

Cuando el Iсом (International Council of Museums, perteneciente a la UnesCo) define el museo o espacio museístico, lo hace de forma muy clara y concisa. Dice que es un espacio abierto al público al servicio de la sociedad y su desarrollo, que exhibe, conserva, investiga, comunica y adquiere con fines de estudio, educación y disfrute, la evidencia material de la gente. El museo es el límite de lo temporal con lo que quiere ser atemporal. Traspasar la puerta de un museo es algo más que entrar en un espacio, es pasar de un lugar donde el tiempo avanza para adentrarnos a un lugar que quiere estar detenido. Aunque no siempre lo consiga, intenta ser atemporal, traducido esto en sus formas, colores, texturas y hasta olores o sabores. Dentro de un museo surge una serie de relaciones, de contaminaciones (Améndola, 2000, p. 243). Por un lado, la confusión entre el arte y el consumo; y por otro y fundamental, el intento de experimentar. Para ello es necesario borrar la relación con el tiempo exterior. Cuando uno se adentra en un museo, detiene el reloj y lo sincroniza según una nueva hora. El acierto en este proceso de ascesis temporal será el que garantice la experiencia.

Lo mismo ocurrirá en la ciudad histórica. Como veremos en las tres escalas analizadas, el intento de detener la historia en un instante concreto será un elemento fundamental para esta puesta en valor. El punto de detenimiento del 
tiempo será elegido en función de la singularidad del mismo para ofertar una opción diferente y, por tanto, un atractivo más.

c. En una experiencia totalizadora. La nueva ciudad, fragmentada tras la implosiónexplosión posmoderna, generará incoherencias físicas y sociales y conformará una ciudad de trozos. La historia ocupará el papel del conglomerante que dé unidad y podrá proporcionar al ciudadano una respuesta a la continua y frustrada búsqueda de totalidad que no encuentra en la ciudad. La ciudad actual no es la respuesta de síntesis y unificación que en otros tiempos fue. La historia, en tanto en cuanto se traduce en comportamientos de identidad, procesará estos ámbitos para bajarlos a la escala del ciudadano. Siendo así, podemos decir que el patrimonio histórico en los centros de las ciudades configura un catalizador de referencias. La gran metrópoli impedirá cualquier intento de este acercamiento al individuo (Soja, 2008). La historia reflejada en el patrimonio físico permite un acercamiento directo que será la única experiencia demandada por el visitante. Hoy las ciudades se proponen, cada vez más, como experiencias museísticas de inmersión total (Améndola, 2000, p. 242). La experiencia totalizadora que demanda el nuevo turista sumergirá al ciudadano para ocupar el papel de actor.

Recientemente era portada en prensa un hecho singular que ocurría en Calvià (Baleares, España). Allí, los taxistas se enfrentaban con las prostitutas por, aparentemente, dar una imagen de inseguridad. Se escucharon voces que decían "estamos cansados de que las prostitutas roben y agredan físicamente a los turistas. Se están cargando el turismo de la zona, y aquí todos vivimos de lo mismo"3. Posiblemente, ni las prostitutas agredieran a los turistas ni incluso les robaran, pero sí proporcionaban inestabilidad al palacio de cristal del turismo balear.

La experiencia totalizadora no lo será solo en cuanto a premisas básicas, sino también en lo que se refiere a contenidos. Se puede ir al Renoir Coffee en Cambridge y escuchar el In Paradisum de Fauré o cruzar la Main Street y entrar en el King's College para ver una exposición de Agnès Poitevin-Navarre. Igualmente podríamos disfrutar de un desfile de modas en el MoMa o admirar una exposición de arte contemporáneo en Bloomingdale's. Los grandes almacenes compiten en cierta medida con los museos en cuanto al contenido, pero será el contenedor del mismo el que cree tensiones entre unos y otros.

\section{Shopping-mall, una hiperrealidad contenida}

Los shopping-mall son cascarones que separan un exterior de otro exterior matizado. Con este anglicismo denominamos un tipo concreto de centros comerciales. Todos tenemos alguno en la retina, dado que últimamente son construcciones frecuentes en los centros de las ciudades. Estas tipologías se multiplican, se diversifican, se complejizan y, con ese espíritu, ganan terreno en las ciudades y modifican los hábitos de consumo de los ciudadanos. El concepto de centro comercial cerrado

http:/ultimahora.es/mallorca/noticia/sucesos/ultimas/enfrentamientos-en-alvia-entre-taxistas-yprostitutas-durante-una-manifestacion.html (24 de septiembre de 2011). 
o shopping-center responde a la lógica de consumo propia de los años ochenta y noventa, en sintonía con la reproducción de los malls en Estados Unidos, resultado de combinar las actividades de ocio y de compra en espacios cerrados. Su evolución ha sido exponencial. Así, encontraremos esta tipología comercial extendida ya por toda la geografía, aunque será en Estados Unidos donde puede trazarse claramente una línea de evolución. Según G. Tella (2009, p. 11), los podríamos clasificar en:

- Shopping-centers reciclados: los primeros complejos tuvieron una localización sobre áreas centrales y estaban basados en el reciclaje de edificios industriales decimonónicos desafectados.

- Shopping-centers periféricos ex novo: sin interrupción del anterior proceso, se inició una etapa de construcción de nuevos edificios, con un lenguaje altamente atractivo, de gran tamaño y situados sobre áreas periféricas.

- Shopping-centers periféricos reciclados: finalmente, a mediados de los años noventa se sumó una nueva instancia, la de los shoppings barriales o de vecindad, usualmente construidos como resultado de operaciones de reciclaje, pero en una escala reducida en relación con los anteriores.

Todos ellos tienen una estructura común, un trozo de ciudad cosificado, vaciado de su contenido original y colmatado con el uso comercial. Supondrán la frontera entre un espacio donde todo puede ocurrir y un espacio en el que nada que no haya sido programado ocurrirá. Dadas las características descritas, podemos ver el paralelismo entre estos y los centros históricos tematizados. Veamos los rasgos de estos espacios robados al espacio público:

- Son un invento que se separa definitivamente de la temporalidad y la intemperie.

- Se anticipan a todas las necesidades de sus visitantes: no existe ni el frío ni el calor, no hay montaje aleatorio de sonidos mecánicos y naturales, no hay conflicto de estilos (el shopping-mall destruye los estilos incluso cuando pretende conservarlos).

- No existen las diferencias nacionales.

- Se separan de la naturaleza de manera completamente nueva y radical.

- En el shopping-mall respiramos aire reciclado, las luces son siempre artificiales y jamás se mezclan con la luz atmosférica; los sonidos del exterior, por decisión arquitectónica, no deben traspasar las paredes fortificadas del recinto; la ausencia de ventanas niega toda comunicación con el afuera.

- De manera infantil, y con voluntad de producir un efecto de escenografía "ecológica", los patios del shopping-mall no pueden prescindir de sus árboles, los mismos árboles en todo el planeta, indiferentes al desierto que rodea al shopping-mall, o a la ciudad decimonónica en la que se ha incrustado.

- Necesitan, para cumplir adecuadamente sus fines, expulsar cualquier recuerdo del mundo exterior y convertirse en un espacio abstracto y universal.

- Se requiere del verde de los árboles como garantía, precisamente, de que la universalidad tecnológica no deja nada afuera, ni siquiera a los árboles 
que, embutidos en sus macetas y detenidos en la mitad de su crecimiento, son una escenografía de ciencia ficción: hierbas verde esmeralda en un paisaje de silicio.

Estas características se reflejan de forma clara en los nuevos centros comerciales conformados en los centros históricos. Dicha comercialización es vista como la alternativa viable para las zonas patrimoniales. El análisis de las principales experiencias de revitalización de centros urbanos llevadas a cabo tanto en España como en el extranjero (Estados Unidos, Canadá, Gran Bretaña, Francia, Bélgica y Suecia, básicamente), nos indica que para lograr la revitalización comercial de los centros históricos, es necesario implantar un modelo de relación entre todos los agentes involucrados en la zona (vecinos, propietarios de los inmuebles, administraciones públicas, empresarios, etcétera) que desemboque en la creación de una asociación global con capacidad de gestión integral. Esta es la solución que desde los gobiernos y desde los estudios económicos se suele dar al planteamiento de la revitalización de las zonas históricas de la ciudad: hacer un ámbito comercial justificándolo de la siguiente manera: "Para lograr la recuperación funcional del centro, hay que entender que lo realmente importante no son los inmuebles, sino los usos que de ellos se pueda hacer sin romper drásticamente con el pasado" (Molinillo, 2000, p. 95). Esto solo es posible si se produce "una estrecha colaboración entre los poderes públicos y los agentes sociales de las zonas afectadas, de tal forma que se articulen mecanismos que permitan la ejecución de las actuaciones respetando el equilibrio de los diferentes intereses puestos en juego" (Id., p. 97); es lo que Hardoy y Gutman (1992) denominan "gestión colaborativa" de las estrategias integrales de intervención, con la participación de los distintos niveles de la Administración y de la población beneficiaria (Id., p. 99).

Por otro lado, si analizamos los requerimientos que desde la Confederación de Cascos Históricos (Madrid) se les pide a estos, comprendemos que ese es el modelo apropiado y que se busca. Los fines de la Confederación se resumen en:

- Defender del Estado el comercio y las actividades mercantiles en los cascos históricos de las ciudades y pueblos.

- Facilitar información sobre las actuaciones de las Administraciones y organismos públicos y privados en los centros históricos.

- Facilitar la gestión de todas aquellas actuaciones encaminadas al desarrollo y la promoción de los cascos históricos.

- Asesorar sobre las actuaciones de las Administraciones y los organismos públicos y privados en los centros históricos que afecten a las actividades de los asociados y al desarrollo de los centros históricos.

- Trabajar para la mejora general de los cascos históricos, teniendo en cuenta la conservación de su patrimonio.

- Lograr cuantos fines sean posibles a través de la Confederación de Cascos Históricos, en orden a la defensa de los intereses de todos los asociados y de sus ciudades ${ }^{4}$.

Fuente: http://www.cocahi.org/ 
Será, por tanto, lógico ver el resultado actual de intervenciones en los centros históricos si los requerimientos que a estos se les piden son los definidos por la citada Confederación.

Cuando Adolfo Vásquez define el hábitat contemporáneo en su artículo "Peter Sloterdijk y Walter Benjamin; Air conditioning en el mundo interior del capital" (2009), dice que el hábitat del ser humano no es ya ni la naturaleza en estado puro ni la casa o el domicilio, sino una organización intermedia que asegure la calidad urbana de la estancia humana. De aquí la necesidad del Estado del bienestar de sentirse dentro de un gran "palacio de cristal". Estas demandas de la nueva sociedad tendrán su reflejo en los centros históricos, como una parte más de la desmembrada ciudad. Estos entornos tematizados se caracterizarán por la necesidad de esferas protectoras que den cobijo a los símbolos identitarios de la ciudad. Ese palacio de cristal urbano en que se han convertido los centros históricos, con sus calles peatonales y sus casas con aire acondicionado, parece constituir una respuesta adecuada a ese deseo de protección. Ya lo decía Walter Benjamin refiriéndose a la época de la Restauración en Francia, cuando hablaba de las galerías comerciales, los pasajes y los mercados de París. Según Benjamin, al construir esos pasajes, el régimen de Napoleón III mostró su verdadera naturaleza, la de intentar transformar el mundo interior en una especie de fantasmagoría: un gran salón abierto donde uno recibe al mundo sin estar obligado a salir de su casa. Para él, ese era el fantasma burgués de base: querer disfrutar de la totalidad de los frutos del mundo sin tener que salir de la propia casa.

El paralelismo del palacio de cristal (shopping-mall) y el ámbito urbano que conforma un centro histórico no es nada nuevo. Hay muchos autores que hablan de la fragilidad del mismo. Así, Fernández Salinas (2005), que escribe sobre la alarmante preocupación del estado de los centros históricos, subrayará que "volver al centro histórico como objeto de reflexión parece una acción oportuna y necesaria" (s/p). Igualmente, y refiriéndose a la problemática de transformación de los mismos, López de Lucio (2008) alerta de los riesgos que corren los tejidos históricos de nuestras ciudades. Esta fragilidad, representada en la imagen de "palacio de cristal", por la fugacidad del material construido, también se traducirá en la tensión que transmite. Ninguna construcción en cristal ha sido nunca sinónimo de tranquilidad, estabilidad y perdurabilidad; todo lo contrario, ha sido fiel reflejo de inestabilidad, fugacidad y vértigo. Pues bien, esas serán las características que entresaquemos de los centros históricos desde los numerosos estudios que hoy pueblan las bibliotecas.

La inconsistencia de estos espacios no es nada nuevo, sino que ya se viene advirtiendo desde los comienzos del tiempo posindustrial (Campesino, 1991). Habrá numerosos autores que planteen alternativas desde la austeridad (Campos Venutti, 1981) hasta todo lo contrario, y otros que se replanteen el modelo de estructuración económica (Hall, 1992, p. 6).

Entre todo este magma de publicaciones hay varios hilos conductores: la problemática de los centros históricos, el papel de los mismos en el urbanismo contemporáneo y su debilidad, tanto en lo material como en lo inmaterial. Igualmente ocurrirá con la escala, encontrándose desde autores que considerarán dicho papel como problema anecdótico, por resolver puntualmente, hasta los que lo analizarán desde una escala mayor, una escala de ciudad. Por otro lado, y dentro de la 
preocupación de abordar esta problemática acuciante, aparecen los modelos de indicadores como herramientas para clarificar y definir, de forma más precisa, objetivos e impactos. Serán de gran ayuda para modelos objetivables, como la clasificación, ordenación y determinación del estado de los centros, pero no lo serán tanto cuando abordemos los modelos sociales. Esta será una de las demandas que se haga a este modelo (López Morales, 1999, p. 105).

\section{Patrimonio y mercado: singularizar, valorar y preservar}

Si incluimos un apartado sobre la relación entre el patrimonio histórico y el mercado es porque, como venimos diciendo, ahí radica gran parte del problema o del potencial que desarrolla esta investigación, y porque es innegable que la cultura, y más concretamente el patrimonio, se han convertido en un tipo de mercancía. El mercado suele objetualizar o cosificar toda realidad con potencial de ser transada. Esto también ocurre con el patrimonio y con el hecho patrimonial. Puede tratarse de ritos, relatos, lugares, etcétera (Godelier, 1996). Tal como entendemos y analizamos, los objetos patrimoniales suelen ser guardados y expuestos para ser musealizados. Se separan de su ámbito original, se reservan, se almacenan, se retiran de la circulación para conservarlos y protegerlos. Este triple proceso de singularizar, valorar y preservar será el que vaya conformando la idea de centro histórico como gran centro musealizado en el que el mercado entrará para acabar haciendo, en todos los sentidos, un lugar para el comercio.

A su vez, esta trilogía de mecanismos será la que nos determine tres escalas en el proceso de "tematización" o puesta en mercado de la herencia (Franquesa, 2010). Procedemos a explicar cada uno de estos niveles a partir de David Harvey (2007).

El primero de los niveles o etapas sería el de la singularización. Se singulariza todo aquello a lo que se le da un valor no común, todo aquello que es diferente por un valor inherente, único. Será la primera etapa dentro de este proceso de puesta en valor, ya que sin reconocimiento de valores singulares no se podrá nunca llegar a hacer una identificación distintiva. La historia es la que confiere este carácter identitario al patrimonio u objetos patrimoniales, así como hay ciertas prácticas y discursos asociados que otorgan validez e instrumentación a tal lectura. Este proceso de singularización, dentro del patrimonio histórico, tiene tres escalas o hitos. El primero sería el reconocimiento público. No se singulariza lo que no recibe valores de la comunidad. Esta sería la escala más básica, en la que tendrían cabida la iglesia del pueblo, la plaza, etcétera. Avanzando, entraríamos en el reconocimiento de valores de elementos comunes que están siendo transformados, dando trascendencia a los que permanecen inalterados. Aquí podríamos reconocer la arquitectura vernácula que no fue pasto de las transformaciones y crecimientos en altura de los años setenta y ochenta. La última escala dentro de la singularidad sería el alto precio reconocido fuera de los límites de la comunidad, el reconocimiento exterior.

En segundo nivel situamos el proceso de valoración. Será un paso más dentro del mecanismo de puesta en valor. Aquí ya se ha reconocido previamente una identidad singular, pero se le adhiere un discurso que es otro valor en sí. La singularización sería una simple delimitación: la iglesia del pueblo, el monumento, etcétera. Ahora estos elementos se enmarcan dentro del reconocimiento de un trabajo realizado, 
adquiriendo -como dice J. Franquesa (2010) - un valor sui generis. En este segundo nivel podríamos subrayar también tres escalas importantes que se irán dando procesualmente. En primer lugar, el valor del contexto y del proceso. Aquí los elementos singularizados serán piezas clave dentro de un discurso y sin valor aparente fuera de él. En segundo lugar, el valor de elementos que en sí niegan el valor de lo económico: "La economía se ocupa de preservar todos los ámbitos que deben mantenerse como sacrosantos. Pero, como es sabido, también las cosas aparentemente no veniales tienen su precio. La dificultad de convertirlas en dinero radica en que son fabricadas con la intención de una expresa negación de lo económico" (Bourdieu, 2001, p. 134). Una tercera escala sería el reconocimiento del valor de la institución, así como el poder establecer evaluaciones comparativas con otros objetos semejantes. Aquí desempeńaría un papel muy importante el museo como aglutinador de diferentes objetos entre los que se puede establecer evaluaciones comparativas. La cercanía de unos con otros, la descontextualización de los mismos y el intento de establecer relaciones entre ellos, serán fundamentales para pasar al siguiente nivel.

El tercer y último nivel es el de la preservación, la cual lleva implícita la protección del objeto o del conjunto de objetos, a los que se les saca de la libre circulación. Esta protección será de carácter objetual. El elemento será aislado de su contenido generador, tras pasar por un proceso de asepsia, para acoger el contenido que se le haya otorgado en el proceso de valoración. La preservación garantizará que estos "iconos de un pasado" se mantengan en el presente para garantizar la individualidad, la exclusividad. Para poderlo ejemplificar, miremos el tema que nos centra en la investigación: los centros históricos. Este proceso implicará la eliminación de todo aquello que obstaculice la apreciación de su valor. "Por otro lado, no debemos olvidar que si bien la forma de valor se refiere a su 'valor extraordinario', este suele ir en paralelo a su valor económico, y así en el ejemplo de la reforma de un centro histórico sabemos que este tipo de procesos implica el incremento de su valor inmobiliario o turístico; es más, es tal incremento aquello que suele motivar la preservación" (Fraquesa, 2010, p. 53).

\section{Ventajas e inconvenientes de un presente inmóvil}

Hemos de ser conscientes en todo momento de que la sociedad, en una gran escala, no ha dejado de hacerse paulatinamente más urbana y tiende a aglomerarse cada vez más. Solo en Estados Unidos, 243 millones de personas se concentran en el 3\% urbano del país ${ }^{5}$. Esta sociedad que tiende al sinecismo ${ }^{6}$ (Soja, 2008, p. 41) se ha acrecentado en los últimos ańos, durante los tiempos de bonanza económica. Así, la ciudad, como si se tratara de la sección de un árbol, ha ido marcando en su trazado

En julio de 2009, la población de Estados Unidos era de 307.006.550 personas, y el 79\% de ellas vivía en territorio urbano. Así la población urbana estadounidense es de 242.535.175 personas. Fuente: United States Department of Agriculture, Economic Research Service (http://www.ers. usda.gov/publications/EIB14/eib14g.pdf).

6 Sinecismo: término usado por E. Soja (2008), para explicar la "interdependencia económica y ecológica y las sinergias creativas, así como también destructivas, que surgen del agrupamiento intencionado y de la cohabitación colectiva de la gente en el espacio, en un hábitat 'hogar”' (p. 42). 
urbano los tiempos de expansión económica e irá marcando ahora los de la actual recesión. El análisis dendrocronológico que harán el urbanismo y la economía nos mostrarán un presente paralizado, sin la inercia de la expansión pasada.

Los centros históricos se enfrentan a profundos cambios funcionales y sociales. En ellos se imbrican centralidades históricas, económicas, culturales, turísticas y simbólicas. También se configuran realidades urbanas conflictivas donde conviven en tensión permanente viejas y nuevas funciones: es lo que conocemos como la tensión del cambio (Troitiño, 2003). La planificación urbana está teniendo dificultades para adaptar los paisajes del pasado a las necesidades del presente, más aún si cabe en este momento de crisis económica. Hace un tiempo leíamos en la prensa (El Confidencial, 1 de mayo de 2011): "Los visados para rehabilitar viviendas cayeron un $4,1 \%$ interanual hasta febrero, con 4.225 certificados solicitados, pese a que el Gobierno aprobó en abril de 2010 la aplicación de una deducción del 10\% en el IRPf [Impuesto sobre la Renta de las Personas Físicas]”. Se trata de un dato muy significativo sobre la magnitud de inversiones y, por tanto, de movimientos y planteamientos en los centros históricos.

En la ciudad contemporánea, la idea del límite al planeamiento no ha sido puesto por ningún soporte físico o límite administrativo; como estamos viendo, lo ha puesto el impacto económico (Ezquiaga, 2009, p. 146). El crecimiento de la construcción en España entre 1996 y 2007 ha sido del 5\% anual, con un incremento del 30\% en el parque de viviendas desde 1998 (Arellano \& Bentolila, 2009). La extraordinaria expansión en ingeniería civil y construcción de edificios ha dado lugar a una especialización productiva hacia actividades relacionadas con la construcción. Dicha especialización no solo se reflejó en el empleo, con cifras de ocupación en la construcción que duplicaban las de Alemania o Reino Unido, sino también en la manipulación, alteración y modificación del suelo construido existente.

El paisaje cultural heredado es una realidad urbana dinámica donde los problemas de reorganización interna, ya sean de reforma, renovación, protección o recuperación, han estado siempre presentes. Por ello, no existe una vía única de intervención en los centros históricos, primando en unos casos planteamientos conservacionistas $y$, en otros, posturas enmarcadas en estrategias de recuperación de naturaleza más integral. Siempre que en la historia se producen cambios socioeconómicos de gran calado, como el que vivimos ahora, hay que replantearse en nuevos términos la cuestión de la funcionalidad de los centros históricos. El presente actual, más que verlo como un momento amenazante por las escasas inversiones en las zonas históricas, habrá que analizarlo desde la perspectiva de un tiempo de reposo en el que valorar, estudiar y discretizar qué planteamos para el futuro.

\section{Conclusiones}

La ciudad histórica, en tanto que recurso turístico, es un bien escaso, no renovable y no reducible a mercancía; por lo tanto, su utilización debe partir de esta premisa, lo que nos lleva a la exigencia de regulación de los flujos turísticos, estableciendo aforos que permitan que los sitios patrimoniales se visiten sin una masificación 
degradante; establecer, en suma, la relación adecuada entre espacio, visitantes y equipamientos requeridos por los mismos.

Por otro lado, una relación adecuada entre espacio y usuario permite comportamientos cívicos que redundan beneficiosamente no solo en la preservación material, sino en la propia imagen de la ciudad percibida por el visitante, posibilitándose de esta manera una experiencia estética de calidad.

La naturaleza económica secundaria del patrimonio cultural en general, y del patrimonio arquitectónico en particular, como venimos viendo durante todo el desarrollo de la investigación, se ha convertido en su naturaleza esencial. Ante todo, el patrimonio es considerado como factor económico, lo mismo que el usuario. La experiencia de encuentro (patrimonio-turista) reviste hoy un interés y entendimiento prevalentemente mercantil. De hecho, esa relación concreta se analiza principalmente dentro del ámbito de la "economía de la experiencia". Pero la relación del hombre con el patrimonio histórico no puede estar determinada fundamentalmente por su carácter económico; abarca el sentido de la vida, la memoria del pasado, el estímulo y la necesidad de la belleza, y posee, por tanto, un valor metaeconómico. La reconsideración del patrimonio en su carácter metaeconómico sería la base de una gestión distinta, con un sentido humanista del que hoy en gran parte carece.

En la Declaración de Manila sobre el Turismo Mundial (1980), en un principio establecido por la propia Organización Mundial del Turismo, se afirma que "en la práctica del turismo, sobre los elementos técnicos y materiales deben prevalecer los elementos espirituales" ( $\$ 21)$, lo que equivale al reconocimiento de su valor metaeconómico, hoy negado.

La tendencia actual del crecimiento de la población mundial y el estándar occidental de modo de vida entran en contradicción. La población mundial en su totalidad no puede alcanzar un bienestar basado en la idea de no limitación y despilfarro. Si esto es cierto en la esfera de los recursos naturales, lo es especialmente para ciertos modos de consumo cultural.

Hoy la población mundial que goza del privilegio de viajar y visitar monumentos, tanto por formación como por capacidad económica, es una relativa minoría. Si esta práctica, y el modo actual de realizarla, se generalizaran a toda la población del planeta, no habría forma de satisfacerla. La solución está no solo en el objetivo demográfico de una población estable frente al actual crecimiento exponencial, sino en un cambio radical del modo de vida y su relación con el patrimonio.

Frente a una sociedad consumista, obsesionada por el crecimiento y que todo lo transforma en mercancía -recursos naturales, patrimonio cultural-, es necesaria la búsqueda de una sociedad satisfecha en términos humanos cuyo fin no sea tener más, sino tener lo suficiente, profundizando en las auténticas necesidades humanas y no identificando posesión y consumo con calidad de vida. La traducción en el campo del patrimonio arquitectónico sería una relación distinta del visitante con aquel, no en términos cuantitativos y de consumo, sino en la búsqueda de una calidad de la experiencia que no depende del número de monumentos visitados, sino de la intensidad de la mirada. 
Todo esto nos lleva a argumentar que proceder de la manera más racional posible a la recuperación de los centros históricos debería suponer, como primera medida, caracterizarlos, entenderlos y comprenderlos como ámbitos en continuo diálogo/ tensión con la ciudad que los contiene. Un acercamiento, científico y disciplinar, que solo ponga en evidencia sus contenidos patrimoniales no haría más que contribuir a su alejamiento y, por tanto, marginación respecto de la ciudad y al territorio en los que están integrados. Caracterizar los centros históricos como piezas patrimoniales, al margen de vinculaciones sociales, los predispone a comportarse como espacios al margen de la ciudad, colaborando con ello a la construcción de un modelo urbano segregado e introduciendo, por esa vía, desequilibrios en la manera de proceder al desarrollo de la ciudad, a la construcción de una nueva herencia, de un nuevo patrimonio.

\section{Referencias bibliográficas}

Agamben, G. (2005). Profanaciones. Barcelona: Anagrama.

Álvarez Mora, A. (2009). La vivienda como indicador de la recuperación de los conjuntos históricos. Un balance en España. En Simposio Internacional Ciudad sobre Ciudad. Interferencias entre pasado y presente urbano en Europa. Valladolid, Fundación del Patrimonio Histórico de Castilla y León, 2009.

Améndola, G. (2000). La ciudad postmoderna. Madrid: Celeste Ediciones.

Arellano, M. \& Bentolila, S. (2009). La burbuja inmobiliaria: causas y responsables. La crisis de la economía española. Lecciones y propuestas. FEDEA, http://www.crisis09.es/ebook/.

Augé, M. (2004). Los no lugares. Una antropología de sobremodernidad. Barcelona: Gedisa.

Banco Interamericano de Desarrollo. (1994). Programa de Revitalización del Centro Histórico de Quito, Fase I. Informe del proyecto. División de Modernización del Estado y Sociedad Civil 3. Washington, D.C.: Banco Interamericano de Desarrollo.

Bourdieu, P. (2001 [1985]). Las formas del capital. Capital económico, capital cultural y capital social. En P. Bourdieu, Poder, derecho y clases sociales (2a ed., pp. 131-164). Bilbao: Desclée de Brouwer. Versión digitalizada en http://bit.ly/19k3FLC

Campesino, A. J. (1991). Política urbanística en centros históricos españoles. XII Congreso Nacional de Geografía. Universitat de València (pp. 411-417). Valencia: Asociación de Geógrafos Españoles.

Campos, G. (1981). Urbanismo y austeridad. Madrid: Siglo XxI.

Carta de Atenas para la restauracion de monumentos históricos. (1931). Adoptada en la Primera Conferencia Internacional de Arquitectos y Técnicos de Monumentos Históricos, Atenas, 1931. Recuperada de http://bit.ly/1cpi0e3

Carta de Atenas. (1933). Redactada en el Cuarto Congreso Internacional de Arquitectura Moderna (CIAM) celebrado a bordo del Patris II, publicada en 1942 por J. L. Sert y Le Corbusier. Recuperada de http://www-etsav.upc.es/personals/monclus/cursos/CartaAtenas.htm 
Carta de Venecia. (1964). Carta internacional sobre la conservación y la restauración de monumentos y sitios. Segundo Congreso Internacional de Arquitectos y Técnicos de Monumentos Históricos, Venecia 1964. Recuperada de http://www.icomos.org.mx/ venecia.php

Declaración de Manila sobre el Turismo Mundial (1980). Realizada por la Conferencia Mundial del Turismo, organizada por la Organización Mundial del Turismo reunida en Manila, Filipinas, del 27 de septiembre al 10 de octubre de 1980. Recuperada de http://turismosostenible.net/documentos/declaracion-de-manila-sobre-el-turismo-mundial/

Ezquiaga, J. M. (2009). Crisis y refundación de la planificación espacial. En V. Urrutia, I. Zubero, A. Izaola \& A. de la Peña (Eds.), Las dimensiones sociales de la ciudad (pp. 145-158). Bilbao: Universidad del País Vasco.

Fernández Salinas, V. (2003). Vivienda modesta y patrimonio cultural: los corrales y patios de vecindad en el conjunto histórico de Sevilla. Scripta Nova, Revista Electrónica de Geografia y Ciencias Sociales, 7(146 - 070). Recuperado de http://www.ub.edu/geocrit/ $\mathrm{sn} / \mathrm{sn}-146(070) \cdot \mathrm{htm}$

Fernández Salinas, V. (2005). De la protección a la legitimación social del patrimonio urbano en Espańa, Scripta Nova, Revista Electrónica de Geografia y Ciencias Sociales, 9(194 041). Recuperado de http://www.ub.edu/geocrit/sn/sn-194-41.htm

Franquesa, J. (2010). Una aproximación al patrimonio desde la antropología económica: la patrimonialización como guardar. En C. del Mármol, J. Frigolé \& S. Narotzky (Eds.), Los lindes del patrimonio. Consumo y valores del pasado (pp. 39-57). Barcelona: Icaria-ICA.

Godelier, M. (1996). El enigma del don. Barcelona: Paidós.

Grimal, P. (1991). Diccionario de mitología griega y romana (pp 368-372). Barcelona: Ediciones Paidós.

Hall, P. (1992). Cities of tomorrow. An intelectual history of urban plannign and design in the twentieth century. Oxford: Basil Blackwell.

Hardoy, J. E. \& Gutman, M. (1992). Impacto de la urbanización en centros históricos de Iberoamérica. Madrid: Ed. Mapfre.

Harvey, D. (2007 [2001]). Espacios del capital. Madrid: Akal.

ICOMOs (International Council on Monuments and Sites). (1987). Carta Internacional para la Conservación de Ciudades Históricas y Areas Urbanas Históricas (Carta de Washington 1987). Adoptada en la Asamblea General del icomos en Washigton, D.c., en octubre de 1987. Recuperada de http://www.esicomos.org/nueva_carpeta/info_DOC_ CIUDADESHISTO.htm

Innerarity, D. (2006). El nuevo espacio público. Madrid: Espasa.

Instituto de Estudios Turísticos de España. (2012). Informe anual. Madrid: Ministerio de Industria, Turismo y Energía. Recuperado de http://bit.ly/1l3XymI

López de Lucio, R. (2008). Los tejidos históricos como espacio museístico o como ciudad vivida. ¿Diseño para el uso o para la estética? En A. García \& A. Conti (Coords.), Espacio público, ciudad y conjuntos históricos (pp. 68-77). Sevilla: Junta de Andalucía, Consejería de Cultura.

López, F. J. (1999). Un buen comienzo: indicadores para la evaluación del estado de conservación de ciudades históricas. Cuadernos Indicadores para la evaluación del estado de conservación de ciudades históricas (pp. 12-42) Granada: Instituto Andaluz de Patrimonio. 
Lynch, K. (1985 [1981]). La buena forma de la ciudad. Barcelona: Gustavo Gili.

Ministerio del Interior, Subsecretaría de Desarrollo Regional y Administrativo (subdere). (2009, agosto). Informe Final de Evaluación, Programa de Recuperación y Desarrollo Urbano de Valparaiso (PRDUV). Versión electrónica en http://www.dipres.gob.cl/574/ articles-49593_doc_pdf.pdf

Molinillo, S. (2000). Centros comerciales de área urbana: especial referencia a las relaciones con entidades laterales. Tesis doctoral, Universidad de Málaga, Departamento de Economía y Administración de Empresas. Recuperada de http://www.biblioteca.uma.es/bbldoc/ tesisuma/16283235.pdf

Montréal, Bureau de Design (2007). Imaginer la place d'Armes. Ville UNESCO de Design. Atelier de design urbain en préparation au réaménagement de la Place d'Armes. Appel de candidatures. Montréal: Bureau de Design. Recuperado de http://ville.montreal.qc.ca/ portal/page?_dad=portal\&_pageid=5457,26687641\&_schema=PORTAL

Normas de Quito (1967). Normas de Quito. Informe final de la reunión sobre conservación y utilización de monumentos y lugares de interés histórico y artístico. Recuperado de http:// www.icomos.org/charters/quito.htm

Ruffin, F. (2007). Penser la ville pour que les riches y vivent heureux. Quand la flambée de l'immobilier est dopée par l'apartheid résidentiel. Le Monde diplomatique (Janvier), 14-15. En http://www.monde-diplomatique.fr/2007/01/RUFFIN/14323. Texto completo recuperado de http://bit.ly/1d8YF0I

Sloterdijk, P. (2004). El palacio de cristal. Conferencia pronunciada en el marco del debate Traumas urbanos. La ciudad y los desastres. Centro de Cultura Contemporánea de Barcelona (сССв). Recuperado de http://www.cccb.org/rcs_gene/petersloterdijk.pdf

Soja, E. (2008 [2000]). Postmetrópolis. Madrid: Traficantes de Sueños.

Tella, G. \& Potocko, A. (2009). Los shopping evolucionan como neocentros urbanos. Diario El Cronista, Suplemento Proyectar y Construir; mayo, pp. 10-11. http://www. guillermotella.com/articulos/los-shopping-evolucionan-como-neocentros-urbanos/

Trivelli, P. \& Nishimura, Y. (2010). The sustainability of urban heritage preservation: interventions to support economic and residential investments in urban heritage areas of Latin América and the Caribbean (RG-T1620): Case study Valparaiso. Santiago: Pablo Trivelli y Cía. Ltda. Recuperado de http://www.subdere.gov.cl/sites/default/files/documentos/ articles-81138_archivo_fuente.pdf

Troitińo, M. A. (2003). La protección, recuperación y revitalización funcional de los centros históricos. Ciudades, arquitectura y espacio urbano, 3. Colección Mediterráneo Económico, Instituto de Estudios Socioeconómicos de Cajamar. Recuperado de http://bit.ly/1jMGpQh

UNESCO (2008). Historic districts for all. A social and human approach for sustainable revitalization (July 2008). Recuperado de http://unesdoc.unesco.org/ images/0015/001583/158331e.pdf

Vásquez Rocca, A. (2009). Peter Sloterdijk y Walter Benjamin; Air conditioning en el mundo interior del capital. Nómadas, 22 (Universidad Complutense de Madrid). Recuperado de http://www.redalyc.org/articulo.oa?id=18111430015

Waisberg, M. (2004). Breves referencias al concepto de patrimonio arquitectónico en las últimas décadas. Revista Archivum, 6 (Valparaíso: Universidad de Valparaíso). Recuperado de http://bit.ly/1c8biYM 